\title{
Response to the Letter to the editor
}

\author{
Mikolaj Przydacz $^{1,2} \cdot$ Piotr Chlosta $^{2} \cdot$ Jacques Corcos $^{1}$
}

Received: 14 July 2018 / Accepted: 16 July 2018 / Published online: 2 August 2018

(c) Springer Nature B.V. 2018

\section{Editor,}

We read with great interest the letter to the editor regarding our recent publication discussing urological follow-up of patients with neurogenic bladder secondary to spinal cord injury (SCI) [1]. We agree with the authors of the commentary that we need more studies to develop a potential screening policy for bladder cancer in SCI patients. Currently, there is no test that fulfils the criteria of a proper screening method; thus, regular follow-up of bladder cancer in SCI patients cannot be recommended [2]. With further prospective cohort studies, we will be able to develop a consensus when investigating and screening for bladder cancer in this specific group of patients.

In our opinion, patient- and interviewer-administered questionnaires are important components of successful follow-up of patients with neurogenic bladder secondary to SCI. Even though no evidence was found whether use of these questionnaires has an impact on outcomes from treatment [3], it is a suitable method for assessing the patient's perspective of bothersome symptoms and their impact on the patients' quality of life. The utilisation of validated questionnaires helps to establish baseline measurements and to quantitate the patient's response to treatment. Similarly, it remains unknown which validated questionnaires are the most appropriate for daily practice, and therefore each questionnaire can be used alone or in combination with other questionnaires to improve assessment or monitoring of treatment outcomes.

This reply refers to the comment available online at https://doi. org/10.1007/s11255-018-1943-5.

Jacques Corcos

jcorcos@uro.jgh.mcgill.ca

1 Department of Urology, Jewish General Hospital, McGill University, 3755 Côte-Sainte-Catherine Road, Pavilion E, Montreal, QC H3T 1E2, Canada

2 Department of Urology, Jagiellonian University, Medical College, Krakow, Poland
We do agree with the commentary that urologists who care for SCI patients should be aware of all responsibilities related to overall patient management, including optimising reproductive function. As intermittent self-catheterisation has positive effects on semen motility [4, 5], it is the optimum method of bladder drainage in this specific group of patients. Nevertheless, infertility in SCI patients should be managed by urologists adequately trained in infertility with proper fellowship programs as SCI patients suffering from infertility might be more challenging than infertile patients without neurogenic lower urinary tract dysfunctions.

\section{Compliance with ethical standards}

Conflict of interest The authors declare no conflict of interest.

Research involving human and animal participants This article does not contain any studies with human participants or animals performed by any of the authors.

\section{References}

1. Przydacz M, Chlosta P, Corcos J (2018) Recommendations for urological follow-up of patients with neurogenic bladder secondary to spinal cord injury. Int Urol Nephrol 50(6):1005-1016

2. Gui-Zhong L, Li-Bo M (2017) Bladder cancer in individuals with spinal cord injuries: a meta-analysis. Spinal Cord 55(4):341-345

3. Corcos J, Przydacz M (2017) Medical history and physical examination. In: Corcos J, Przydacz M (eds) Consultation in neurourology: a practical evidence-based guide, 1 st edn. Springer, New York, pp 39-49

4. Ohl DA, Denil J, Fitzgerald-Shelton K, McCabe M, McGuire EJ, Menge AC et al (1992) Fertility of spinal cord injured males: effect of genitourinary infection and bladder management on results of electroejaculation. J Am Paraplegia Soc 15(2):53-59

5. Rutkowski SB, Middleton JW, Truman G, Hagen DL, Ryan JP (1995) The influence of bladder management on fertility in spinal cord injured males. Paraplegia 33(5):263-266 